\title{
The changes in pyroptosis-related inflammatory factors in the peripheral blood of patients with Henoch-Schonlein purpura
}

\author{
Jinpeng Wang", Yuyu Zheng", Genwang Chen, Yiming Lv, Fen Lian, Daqi Jiang, Wanhong Ke, Lili Liu, \\ Chunmei Fan, Sisi Gong \\ Department of Laboratory, Donghai Branch of the Second Affiliated Hospital of Fujian Medical University, Quanzhou, China \\ Contributions: (I) Conception and design: J Wang, Y Zheng, C Fan; (II) Administrative support: G Chen, Y Lv, F Lian; (III) Provision of study \\ materials or patients: D Jiang, W Ke, L Liu, S Gong; (IV) Collection and assembly of data: All authors; (V) Data analysis and interpretation: J Wang, \\ Y Zheng, C Fan; (VI) Manuscript writing: All authors; (VII) Final approval of manuscript: All authors. \\ \#These authors contributed equally to this work. \\ Correspondence to: Chunmei Fan. Department of Laboratory, Donghai Branch of the Second Affiliated Hospital of Fujian Medical University, \\ Donghai Street, Fengze District, Quanzhou 362000, China. Email: Fcmei9575@163.com.
}

Background Henoch-Schonlein purpura (HSP) is a common capillary allergic bleeding disease. To explore the variation of pyroptosis-related inflammatory factors level in the peripheral blood of patients with HSP.

Methods: A total of 87 HSP patients treated in our hospital from June 2020 to March 2021 were selected and divided into the renal impairment group $(\mathrm{n}=29)$ and the non-renal impairment group $(\mathrm{n}=58)$ according to the presence of hematuria and proteinuria. A total of 50 healthy individuals from the hospital were selected as the control group. The renal impairment and non-renal impairment groups were treated with a regular regimen of compound glycyrrhizin tablets and glucocorticoids, respectively. Serum interleukin (IL)-18, IL-1 $\beta$, and peripheral caspase-1-positive cells were compared pre- and post-treatment among the three groups.

Results: The pre-treatment serum IL-1 $\beta$ levels in the renal impairment and non-renal impairment groups were significantly higher than that in the control group $(\mathrm{P}<0.01)$. After treatment, the IL-1 $\beta$ level in the nonrenal impairment group was not significantly different from that in the control group $(\mathrm{P}>0.05)$. However, the IL-1 $\beta$ level in the renal impairment group post-treatment was significantly higher than that in the other two groups $(\mathrm{P}<0.01)$. The positive rate of caspase-1 expression in peripheral blood before treatment in the renal impairment group and non-renal impairment group was significantly higher than that in the control group $(\mathrm{P}<0.01)$. After treatment, the positive rate of caspase-1 expression in the non-renal impairment group was comparable to that in the control group $(\mathrm{P}>0.05)$, whereas the rate in the renal impairment group was significantly higher than that in the other two groups $(\mathrm{P}<0.01)$. After treatment, the serum IL-1 $\beta$ levels and caspase- 1 positive rate in HSP patients who were responsive to treatment (as assessed by hematuria or proteinuria levels after treatment) were lower than that in patients who were unresponsive to treatment $\mathrm{P}<0.001)$, but not significantly different to the control group $(\mathrm{P}>0.05)$.

Conclusions: The levels of serum IL-1 $\beta$ and caspase- 1 changed in response to alterations in the disease condition and treatment response in HSP patients, which suggested that pyroptosis-related inflammatory factors may have potential application value in predicting disease progression and efficacy of hormone therapy.

Keywords: Henoch-Schonlein purpura (HSP); pyroptosis; IL-1 $\beta$; IL-18; caspase-1

Submitted Apr 14, 2021. Accepted for publication May 28, 2021.

doi: 10.21037/apm-21-1227

View this article at: http://dx.doi.org/10.21037/apm-21-1227 


\section{Introduction}

Henoch-Schonlein purpura (HSP) is an allergic disease primarily involving small vessels throughout the body and is associated with autoimmunity, but the specific etiology and pathogenesis are still unknown. The pathological features of HSP are the capillary blood vessels involved and the deposited immune complex leukocyte destructive vasculitis. The kidney is the main organ involved, and the condition can progress to chronic nephritis and even renal failure without timely or effective treatment. Therefore, to promptly control the progression of the disease and prevent long-term complications and adverse events, early assessment of whether it is complicated by renal impairment and the severity is essential (1). Pyroptosis, a recently identified programmed cell death phenomenon, is characterized by caspase- 1 activation and released of interleukin (IL)-1 $\beta$ and IL-18 (2). The aberrant inflammatory response and immune cell activation caused by excessive pyroptosis may impair the host immune system and even lead to autoimmune diseases. Studies have implicated the role of pyroptosis in the pathogenesis of immune disorders such as HSP $(3,4)$. Both IL- $1 \beta$ and IL-18 are important cytokines released during pyroptosis, while caspase- 1 expression is considered a biomarker of pyroptosis. Several inflammatory factors in serum have been previously reported to be associated with the onset and disease progression of pediatric HSP, but the relationship between pyroptosis cytokines and HSP remains undefined $(5,6)$. In this study, double antibody sandwich enzymelinked immunosorbent assay (ELISA) and flow cytometry were used to analyze the serum levels of IL-1 $\beta$, IL-18, and caspase-1-positive cells in the peripheral blood of HSP patients to investigate the changes and clinical values of pyroptosis-related cytokines in the pathogenesis of HSP.

We present the following article in accordance with the STROBE reporting checklist (available at http://dx.doi. org/10.21037/apm-21-1227).

\section{Methods}

\section{Patients}

A total of 87 HSP patients admitted to Donghai Branch of the Second Affiliated Hospital of Fujian Medical University from June 2020 to March 2021 were enrolled in this study. There were 45 males and 42 females, with an average age of $8.7 \pm 3.4$ years (range, $3-17$ years). Patients were included if they met the 1990 American College of Rheumatology (ARA) revised diagnostic criteria for HSP (3) and they did not present with any infectious manifestations. Participants who had received hormones and immunosuppressants within 3 months, patients with signs of infection or other autoimmune diseases such as lupus erythematosus and severe liver and kidney function impairment, and patients who did not cooperate were excluded from this study. Patients were divided into the renal impairment group $(n=29)$ and the non-renal impairment group $(n=58)$ according to the presence of haematuria and proteinuria within 6 months of disease onset. According to the presence of hematuria or proteinuria after treatment, 19 patients were designated the treatment responsive group and 10 patients were designated the treatment unresponsive group. In addition, 50 cases from the physical examination department of our hospital were enrolled as the control group (mean age of 9.5 years). There were no significant differences among the three groups in terms of gender or age composition $(\mathrm{P}>0.05)$. All procedures performed in this study involving human participants were in accordance with the Declaration of Helsinki (as revised in 2013). The study was approved by the Research Ethics Committee of Donghai Branch of the Second Affiliated Hospital of Fujian Medical University \{No.: [2021] the Second Affiliated Hospital of Fujian Medical University ethics review number (203)\} and informed consent was taken from all the patients.

\section{Blood specimen collection}

In the control group, blood specimens were collected from patients on the first day of admission. For patients in the renal impairment and non-renal impairment groups, blood was collected on the first day of admission and again at 6 months after treatment. At each collection time point, a total of $2 \mathrm{~mL}$ of venous blood was collected in the morning, and the serum was separated and kept at $-20{ }^{\circ} \mathrm{C}$ for later use.

\section{Measurement of IL-1B and IL18 levels in the serum by ELISA}

Serum levels of IL-1 $\beta$ and IL-18 were measured using a double antibody sandwich ELISA (Thermo Fisher Scientific (China) technique with a Hyperion MR model III microplate reader, according to the manufacturer's instructions (Thermo Fisher Scientific, China). 
Table 1 Serum IL-1 $1 \beta$ levels before and after treatment in the three groups $(\mu \mathrm{g} / \mathrm{L}, \bar{x} \pm s)$

\begin{tabular}{|c|c|c|c|}
\hline Category & Number & Pre-treatment & Post-treatment \\
\hline Non-renal impairment group & 58 & $23.25 \pm 2.99$ & $16.82 \pm 1.71$ \\
\hline Control group & 50 & $16.67 \pm 1.49$ & - \\
\hline \multicolumn{4}{|l|}{$\mathrm{F}$ value } \\
\hline Renal impairment group vs. Control group & & 15.27 & 3.79 \\
\hline Renal impairment group vs. Non-renal impairment group & & 8.70 & 3.65 \\
\hline \multicolumn{4}{|l|}{$P$ value } \\
\hline Non renal impairment group vs. Control group & & $<0.001$ & 0.833 \\
\hline
\end{tabular}

\section{Flow cytometry}

Briefly, $20 \mu \mathrm{g} / \mathrm{L}$ phorbol ester, $1 \mu \mathrm{mol} / \mathrm{L}$ ionoxin, and $2 \mu \mathrm{mol} / \mathrm{L}$ monensin were mixed with $1 \mathrm{~mL}$ venous blood and incubated in an incubator for 6 hours. The cells were collected and 7-amino-4-trifluoromethylcoumarin (AFC)labeled murine-anti human caspase- 1 antibody was used for cell surface staining (Abcam, UK). Subsequently, $100 \mu \mathrm{L}$ fixative membrane disruption kit solution A (AAT Bioquestwas, USA) added, cells were fixed, washed, and the supernatant discarded. Cells were then fixed and resuspended in $300 \mu \mathrm{L} 1 \%$ paraformaldehyde phosphate buffered saline (PBS) to be analyzed by the FACS Calibur flow cytometer (BD Biosciences, USA).

\section{HSP treatment regimens}

Patients were administered $2 \mathrm{mg} / \mathrm{kg}$ prednisone acetate tablets daily (Zhejiang Xianju Pharmaceutical, Sinopharm h33021207), which were doses induced after 4 weeks of oral administration. Compound glycyrrhizin tablets (25 or $50 \mathrm{mg}$, Akiyama tablets Zhu, Sinopharm j20130077) were administered orally 3 times daily, and compound rutin tablets $(0.14 \mathrm{~g}$, Ningbo Dalong hawk Pharmaceutical, Sinopharm h33020586) were administered orally, 1 tablet, 3 times daily. Obvious rashes were treated topically with alosone ointment (Bayer Medicine Shanghai), once daily. All patients were administered $2.0 \mathrm{~g}$ intravenous infusion of vitamin C (Xi'an Bosen Pharmaceutical, Sinopharm h61020468), once daily.

\section{Statistical analysis}

The SPSS 22.0 software was used to analyze data. Enumeration data was expressed as percentage (\%), and measurement data was expressed as mean \pm standard deviation (SD). The Fishers LSD $t$ tests were used to compare data among groups, and paired $t$ tests were used to compare data before and after treatment in the same group. Results were considered statistically significant when $\mathrm{P} \leq 0.05$.

\section{Results}

\section{Changes in serum IL-1ß levels in the three groups}

The serum IL-1 $\beta$ levels of HSP patients in both the renal impairment group and the non-renal impairment group before treatment were significantly higher than that observed in the control group $(\mathrm{P}<0.001)$. The IL-1 $\beta$ levels in the renal impairment group were also higher than that in the nonrenal impairment group. After treatment, however, there was no significant difference in the levels of IL- $1 \beta$ between the non-renal impairment group and the control group $(\mathrm{P}>0.05)$, suggesting that the serum levels of IL- $1 \beta$ in these patients had returned to normal. However, the levels of IL-1 $\beta$ in the renal impairment group were still significantly higher than that in the other two groups (Table 1).

\section{Changes in serum IL-18 levels in the three groups}

The serum IL-18 levels in patients in the renal impairment group and non-renal impairment group were not 
Table 2 Serum IL-18 levels before and after treatment in three groups $(\mu \mathrm{g} / \mathrm{L}, \bar{x} \pm \mathrm{s})$

\begin{tabular}{|c|c|c|c|}
\hline Category & Number & Pre-treatment & Post-treatment \\
\hline Non-renal impairment group & 58 & $14.17 \pm 2.07$ & $13.98 \pm 1.71$ \\
\hline Control group & 50 & $13.71 \pm 1.96$ & - \\
\hline \multicolumn{4}{|l|}{ F value } \\
\hline Renal impairment group vs. Control group & & 2.14 & 1.04 \\
\hline Renal impairment group vs. Non-renal impairment group & & 1.83 & 0.77 \\
\hline \multicolumn{4}{|l|}{$P$ value } \\
\hline Non renal impairment group vs. Control group & & 0.38 & 0.49 \\
\hline
\end{tabular}

statistically different to the levels observed in the control group pre-treatment or post-treatment $(\mathrm{P}>0.05$, Table 2).

\section{Changes in peripheral blood caspase-1 expression in the three groups}

Caspase- 1 expression in the peripheral blood before treatment was significantly higher $(\mathrm{P}<0.001)$ in HSP patients with or without renal impairment compared with patients in the control group. Furthermore, the expression was also higher in the renal impairment group compared to the non-renal impairment group. After treatment, however, there was no significant difference in the proportion of caspase- 1 positive cells between the non-renal impairment group and the control group $(\mathrm{P}>0.05)$, suggesting that expression of caspase- 1 in these patients had returned to normal. In contrast, the caspase- 1 levels in the renal impairment group remained significantly higher than that in the other two groups (Table 3).

\section{Serum IL-1ß and blood caspase-1 levels in HSP renal impairment patients who were responsive or unresponsive to therapy}

According to the presence of hematuria or proteinuria after treatment, the 29 patients with renal impairment were divided into the treatment responsive group $(n=19)$ and the treatment unresponsive group $(n=10)$. After treatment, serum of IL- $1 \beta$ and caspase- 1 in the treatment responsive group were significantly lower than those in the unresponsive group $(\mathrm{P}<0.001)$, and there was no significant difference compared with the control group $(\mathrm{P}>0.05)$, as shown in Table 4.

\section{Discussion}

HSP is a common immune vascular disease, often diagnosed in children and adolescents. The clinical manifestations are usually acute, varied, and easily misdiagnosed (7). HSP can easily lead to kidney impairment, and its symptoms are often not consistent with renal pathological changes. If clinicians diagnose or formulate treatment strategies according to clinical manifestations alone, the optimal window for diagnosis and treatment may be missed $(8,9)$.

A large number of studies have shown that HSP is mainly related to the immune abnormality of the body, involving humoral immunity, cellular immunity, and several related cytokines, such as IL-1, 2, 4, 5, 6, 8, 10, $13,15,17$, and $18(10,11)$. IL- 1 and IL-18 are also the main inflammatory factors released during the process of pyroptosis. Pyroptosis is a recently described form of programmed death related to inflammatory cells. It mainly causes the gasdermin D (GSDMD) protein and other proteins to shear or polymerize via caspase- 1 and noncaspase-1 pathways, which leads to cell perforation and death $(12,13)$. While it is a cellular stress response in the presence of bacteria, fungi, or virus infections, pyroptosis also participates in the immune response of pathological processes including tumors, sepsis, and Alzheimer's disease. Therefore, pyroptosis may also play an important role in 
Table 3 Caspase- 1 expression in peripheral blood before and after treatment in the three groups $(\%, \bar{x} \pm \mathrm{s})$

\begin{tabular}{|c|c|c|c|}
\hline Category & Number & Pre-treatment & Post-treatment \\
\hline Non-renal impairment group & 58 & $23.25 \pm 2.99$ & $16.82 \pm 1.71$ \\
\hline Control group & 50 & $16.67 \pm 1.49$ & - \\
\hline \multicolumn{4}{|l|}{ F value } \\
\hline Renal impairment group vs. Control group & & 15.27 & 3.79 \\
\hline Renal impairment group vs. Non-renal impairment group & & 8.70 & 3.65 \\
\hline \multicolumn{4}{|l|}{$P$ value } \\
\hline Non-renal impairment group vs. Control group & & $<0.001$ & 0.833 \\
\hline
\end{tabular}

Table 4 Serum IL-1 $\beta$ and blood caspase-1 levels in HSP renal impairment patients who were responsive or unresponsive to therapy ( $\mu \mathrm{g} / \mathrm{L}, \bar{x} \pm \mathrm{s}$ )

\begin{tabular}{|c|c|c|c|}
\hline Category & Number & Pre-treatment & Post-treatment \\
\hline Unresponsive group & 10 & $26.55 \pm 2.04$ & $4.95 \pm 2.89$ \\
\hline Control group & 50 & $16.67 \pm 1.49$ & $4.51 \pm 2.32$ \\
\hline \multicolumn{4}{|l|}{ t value } \\
\hline Unresponsive group vs. Control group & & 14.38 & 44.23 \\
\hline Responsive group vs. Unresponsive group & & 17.96 & 11.65 \\
\hline \multicolumn{4}{|l|}{$P$ value } \\
\hline Responsive group vs. Unresponsive group & & $<0.001$ & $<0.001$ \\
\hline
\end{tabular}

the pathogenesis and disease transformation of HSP.

Serum levels of IL-1 $\beta$ and IL-18 were measured by ELISA. Compared with control patients, the serum IL-1 $\beta$ levels in HSP patients were significantly higher, especially in HSP patients with renal impairment. The serum levels of IL-1 $\beta$ in HSP patients in the non-renal impairment group recovered to normal levels after treatment, which suggested that IL-1 $\beta$ may be used as an indicator of the severity of the disease and a measure of therapeutic efficacy. Dinarello et al. (14) reported that the IL-1 family is mainly related to acute and chronic inflammation, and IL- $1 \beta$ has become a therapeutic target of many autoimmune diseases. This latter study suggested that inhibiting the effects of IL-1 $\beta$ could reduce the severity of the disease, which is consistent with our results. However, regardless of treatment, the levels of IL-18 in the renal impairment group and the nonrenal impairment group were not statistically different compared with the control group, which may be due to the 
different roles of IL-18 and IL- $1 \beta$ in HSP. Although IL-18 is structurally homologous with the IL-1 family, and its receptor belongs to the IL-1R/toll-like receptor (TLR) superfamily, its function is completely different from IL-1. IL18 can be produced not only by immune cells but also by non-immune cells. IL-18 alone can stimulate helper T cell type (Th2)-mediated cytokine production and cause allergic inflammation (15). In coordination with IL-12, IL-18 can stimulate the helper T cell type 1 (Th1) mediated immune responses. Therefore, the function of IL-18 in vivo is complex. Although IL-18 and IL- $1 \beta$ participate in the process of pyroptosis, they may have different mechanisms and downstream pathways in HSP, and future studies examining their roles in the pathogenesis and treatment of refractory HSP is warranted.

Flow cytometry demonstrated that the number of caspase-1 positive cells in the peripheral blood of HSP patients was greater than that in the control group, and the number of caspase-1 positive cells in the renal impairment group was higher than that of the other two groups. The expression of capase- 1 positive cells in HSP patients in the non-renal impairment group recovered to normal after treatment. These changes in caspase- 1 expression and the

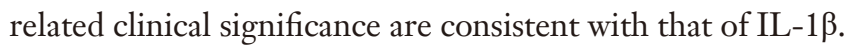
In fact, during the process of pyroptosis, inflammasomes promote the secretion of IL-1 $\beta$ by activating caspase-1 (16). However, in our study, the level of caspase- 1 or IL-1 $\beta$ in the renal impairment group was still higher than that of the other two groups. This could be related to the patients' response to hormone therapy. Therefore, the levels of IL- $1 \beta$ and caspase- 1 in the peripheral blood of patients with and without negative urine protein post-treatment were compared. In the renal impairment group, patients with negative urine protein after treatment and were thus responsive to treatment, showed decreased levels of serum IL- $1 \beta$ and caspase- 1 , and these levels were comparable to that observed in the control group. In contrast, the levels of serum IL- $1 \beta$ and caspase- 1 in patients who did not show a negative urine protein reading and were thus unresponsive to treatment, remained abnormally high even after treatment. This suggested that the serum IL- $1 \beta$ and caspase-1 levels could be restored to normal levels with the improvements of renal function after effective treatment. In conclusion, the levels of serum IL- $1 \beta$ and caspase- 1 may reflect changes in the patients' condition, renal impairment, and treatment efficacy, suggesting that these pyroptosisrelated inflammatory factors may have potential clinical value as markers of disease progression and hormone therapy efficacy.

\section{Acknowledgments}

Funding: None.

\section{Footnote}

Reporting Checklist: The authors have completed the STROBE reporting checklist. Available at http://dx.doi. org/10.21037/apm-21-1227

Data Sharing Statement: Available at http://dx.doi. org/10.21037/apm-21-1227

Conflicts of Interest: All authors have completed the ICMJE uniform disclosure form (available at http://dx.doi. org/10.21037/apm-21-1227). The authors have no conflicts of interest to declare.

Etbical Statement: The authors are accountable for all aspects of the work in ensuring that questions related to the accuracy or integrity of any part of the work are appropriately investigated and resolved. All procedures performed in this study involving human participants were in accordance with the Declaration of Helsinki (as revised in 2013). The study was approved by the Research Ethics Committee of Donghai Branch of the Second Affiliated Hospital of Fujian Medical University \{No.: [2021] the Second Affiliated Hospital of Fujian Medical University ethics review number (203)\} and informed consent was taken from all the patients.

Open Access Statement: This is an Open Access article distributed in accordance with the Creative Commons Attribution-NonCommercial-NoDerivs 4.0 International License (CC BY-NC-ND 4.0), which permits the noncommercial replication and distribution of the article with the strict proviso that no changes or edits are made and the original work is properly cited (including links to both the formal publication through the relevant DOI and the license). See: https://creativecommons.org/licenses/by-nc-nd/4.0/.

\section{References}

1. Hetland LE, Susrud KS, Lindahl KH, et al. HenochSchönlein Purpura: A Literature Review. Acta Derm Venereol 2017;97:1160-6. 
2. Shi J, Gao W, Shao F. Pyroptosis: Gasdermin-Mediated Programmed Necrotic Cell Death. Trends Biochem Sci 2017;42:245-54.

3. Mills JA, Michel BA, Bloch DA, et al. The American College of Rheumatology 1990 criteria for the classification of Henoch-Schönlein purpura. Arthritis Rheum 1990;33:1114-21.

4. Yuan YY, Xie KX, Wang SL, et al. Inflammatory caspaserelated pyroptosis: mechanism, regulation and therapeutic potential for inflammatory bowel disease. Gastroenterol Rep (Oxf) 2018;6:167-76.

5. Zhu Y, Dong Y, Wu L, et al. Changes of inflammatory mediators and oxidative stress indicators in children with Henoch-Schönlein purpura and clinical effects of hemoperfusion in the treatment of severe HenochSchönlein purpura with gastrointestinal involvement in children. BMC Pediatr 2019;19:409.

6. Davin JC. Henoch-Schonlein purpura nephritis: pathophysiology, treatment, and future strategy. Clin J Am Soc Nephrol 2011;6:679-89.

7. Trnka P. Henoch-Schönlein purpura in children. J Paediatr Child Health. J Paediatr Child Health 2013;49:995-1003.

8. Heineke MH, Ballering AV, Jamin A, et al. New insights in the pathogenesis of immunoglobulin A vasculitis (HenochSchönlein purpura). Autoimmun Rev 2017;16:1246-53.

9. Zhang J, Zeng H, Wang N, et al. Beneficial effects of creatine phosphate sodium for the treatment of HenochSchönlein purpura in patients with early renal damage

Cite this article as: Wang J, Zheng Y, Chen G, Lv Y, Lian F, Jiang D, Ke W, Liu L, Fan C, Gong S. The changes in pyroptosis-related inflammatory factors in the peripheral blood of patients with Henoch-Schonlein purpura. Ann Palliat Med 2021;10(6):6687-6693. doi: 10.21037/apm-21-1227 detected using urinary kidney injury molecule-1 levels. Eur J Pediatr 2016;175:49-55.

10. Yuan L, Wang Q, Zhang S, et al. Correlation between serum inflammatory factors TNF- $\alpha$, IL-8, IL-10 and Henoch-Schonlein purpura with renal function impairment. Exp Ther Med 2018;15:3924-8.

11. Franchi L, Eigenbrod T, Muñoz-Planillo R, et al. The inflammasome: a caspase-1-activation platform that regulates immune responses and disease pathogenesis. Nat Immunol 2009;10:241-7.

12. Frank D, Vince JE. Pyroptosis versus necroptosis: similarities, differences, and crosstalk. Cell Death Differ 2019;26:99-114.

13. Shin JI, Lee KH, Joo YH, et al. Inflammasomes and autoimmune and rheumatic diseases: A comprehensive review. J Autoimmun 2019;103:102299.

14. Dinarello CA. Interleukin-1 in the pathogenesis and treatment of inflammatory diseases. Blood 2011;117:3720-32.

15. Xiao H, Li H, Wang JJ, et al. IL-18 cleavage triggers cardiac inflammation and fibrosis upon $\beta$-adrenergic insult. Eur Heart J 2018;39:60-9.

16. Okondo MC, Johnson DC, Sridharan R, et al. DPP8 and DPP9 inhibition induces pro-caspase-1-dependent monocyte and macrophage pyroptosis. Nat Chem Biol 2017;13:46-53.

(English Language Editor: J. Teoh) 